\title{
Epidemiology of firearm injuries in Sweden
}

\author{
Karolina Nyberger $^{1,2} \cdot$ Eva-Corina Caragounis $^{3} \cdot$ Pauline Djerf $^{4} \cdot$ Carl-Magnus Wahlgren $^{1,2}$ (1)
}

Received: 27 December 2020 / Accepted: 19 June 2021 / Published online: 2 July 2021

(c) The Author(s) 2021

\begin{abstract}
Background Gun violence is a global health problem. Population-based research on firearm-related injuries has been relatively limited considering the burden of disease. The aim of this study was to analyze nationwide epidemiological trends of firearm injuries.

Methods This is a retrospective nationwide epidemiological study including all patients with firearm injuries from the Swedish Trauma Registry (SweTrau) during the period 2011 and 2019. Registry data were merged with data from the Swedish National Council for Crime Prevention and the Swedish Police Authority.

Results There were 1010 patients admitted with firearm injuries, $96.6 \%$ men and $3.4 \%$ women, median age 26.0 years [IQR 22.0-36.3]. The overall number of firearm injuries increased on a yearly basis $(P<0.001)$. The most common anatomical injury location was lower extremity (29.7\%) followed by upper extremity (13.8\%), abdomen (13.8\%), and chest (12.5\%). The head was the most severely injured body region with a median abbreviated injury scale (AIS) of 5 [IQR 3.2-5]. Vascular injuries were mainly located to the lower extremity (42\%; 74/175). Majority of patients $(51.3 \%)$ had more than one anatomic injury location. The median hospital length of stay was 3 days [IQR 2-8]. 154 patients (15.2\%) died within $24 \mathrm{~h}$ of admission. The 30-day and 90-day mortality was $16.7 \%$ (169/1010) and 17.5\% (177/1010), respectively. There was an association between 24-h mortality and emergency department systolic blood pressure $<90 \mathrm{mmHg}$ [OR 30.3, 95\% CI 16.1-56.9] as well as the following injuries with AIS $\geq 3$; head [OR 11.8, 95\% CI 7.5-18.5], chest [OR 2.3, 95\% CI 1.3-4.1], and upper extremity [OR 3.6, CI 1.3-10.1].

Conclusions This nationwide study shows an annual increase of firearm-related injuries and fatalities. Firearm injuries affect people of all ages but more frequently young males in major cities. One in six patients succumbed from their injuries within 30 days with most deaths occurring within $24 \mathrm{~h}$ of hospital admission. Given the impact of firearm-related injuries on society additional research on a national level is critical.
\end{abstract}

Keywords Firearm injury · Gunshot wound · Epidemiology

\section{Introduction}

Violence with firearms is considered to be a complex public health issue [1]. About a quarter of a million people worldwide die from firearm injuries annually, the majority associated with homicides [2]. Gun-related deaths affect men and younger people to a greater extent. Rates of firearm deaths vary among countries and across demographic subgroups. The rate of gun-related mortality is higher in the United States than other high-income countries in the world [3]. However, penetrating trauma has become a highly relevant

Carl-Magnus Wahlgren

carl.wahlgren@sll.se

Extended author information available on the last page of the article issue also in Europe in recent years [4, 5]. Firearm injuries do not only affect the livelihood of those injured but also cause major impact in terms of financial burden on healthcare systems and society [6].

Research on violence with firearms has been relatively limited considering the burden of disease and there is a need for more studies including data on epidemiology and clinical outcome to further improve management of these injuries [7]. The contemporary experience from a single Scandinavian trauma centre has shown an increase in firearm injuries in recent years [8]. It is important to study how firearm injuries affect health care systems on a national level to develop robust trauma systems improving field triage and identifying patients with a need for trauma centre care. In addition, further research may identify areas to implement injury 
prevention strategies. The aim of this study was to analyze nationwide trends in firearm injuries including demographics, operative procedures, and patient outcomes.

\section{Methods}

\section{Study population}

This was a retrospective nationwide epidemiological study including all patients with firearm injuries from the national Swedish Trauma Registry (SweTrau) from January 1, 2011 to December 31, 2019. There were 71,879 trauma patients registered during the study period, of which 1010 patients were identified with firearm injuries (1.4\%). The study was approved by the Ethical Review Agency (2019-05863).

\section{Study aims}

The primary aim was to investigate nationwide epidemiology of firearm injuries during the study period. Secondary aims were to assess anatomical distribution of injuries, operative procedures, and patient outcome.

\section{Data sources}

Data on demographics as well as anatomical localization of injury, surgery, and mortality were extracted from the national trauma registry, SweTrau, which was founded in 2011 [9]. SweTrau is the only nationwide trauma database, covering $84 \%$ of the trauma receiving hospitals in Sweden. The SweTrau database follows "The Utstein Trauma Template for Uniform Reporting of Data Following Major Trauma; Data Dictionary", which represent a uniform set of variables considered most important for comparing trauma systems and outcomes in Europe. Data access for this study was approved by the registry steering committee. Open access data regarding the total number of deaths due to lethal violence were collected from the Swedish National Council for Crime Prevention and data on the annual number of confirmed shootings from the Swedish Police Authority (reports started November 2016).

\section{Inclusion and exclusion criteria}

Patients of all ages and genders, admitted with firearm injuries, were included in the study $(n=1010)$. Patients admitted to the reporting hospital more than $24 \mathrm{~h}$ after injury and patients declared dead before hospital arrival was excluded. To be registered in SweTrau, patients have to fulfill at least one of the following inclusion criteria: Trigger a trauma team activation, have a New Injury Severity Score (NISS) $>15$, or have a NISS $>15$ and be transferred from another hospital within 7 days. Trauma team activations are either Level 1 triggers whereby a large team resucitates trauma patients with physiological impairment and/or with obvious injury, or Level 2 triggers whereby a limited team assesses patients without physiological impairment subjected to a specific mechanism of injury. Injuries that were not caused by firearms were excluded from further analysis $(n=70,869)$. Missing values for specific variables were imputed for some variables and are reported below.

\section{Definitions}

Firearm injuries were defined using the International Classification of Diseases (ICD) codes for injury mechanisms: X93-Assault by handgun X94-Assault by rifle, shotgun, and larger firearm; and X95-Assault by other and unspecified firearm.

According to the Swedish National Council for Crime Prevention, a confirmed shooting is defined as an occasion when projectiles with a gunpowder-charged weapon have been fired, and there are traces of bullets, cartridge cases, or damage to materials or people related to the shooting, or there is more than one independent eyewitness to the firing. The shooting must also be illegal and intentional. Furthermore, the mortality data from the Swedish National Council for Crime Prevention on deaths by firearm injuries were defined by all deaths caused by illegal shootings. Hence, the data included both individuals confirmed dead at the scene and individuals confirmed dead after hospital arrival.

The anatomical classification according to the Abbreviated Injury Scale (AIS) was used to classify anatomical injury location [10]. To minimize missing Revised Trauma Score (RTS) values, unpalpable radial pulse was converted to a systolic blood pressure below $90 \mathrm{mmHg}$ [11]

\section{Statistical analysis}

Data were presented as median with interquartile range (IQR). Descriptive statistics were performed for patient characteristics and outcomes. Univariate analyses of binary and nominal variables were performed using cross-tabulations and values were reported for the Pearson's chi-square and Fisher's exact tests. Univariate analysis and multivariable logistic regression analyses were performed to identify risk factors for 24-h and 30-day mortality post-trauma admission. In the logistic regression model, age, gender, NISS, emergency department systolic blood pressure, and AIS score of injured body regions were all included as covariates. All covariates mentioned were included in both the univariate and multivariate analyses except for NISS in the multivariate analysis due to multicollinearity. The Poisson regression model was used to analyze trauma trends over the years. 
Kaplan-Meier method was used for presentation of survival. $P$ value $<0.05$ was considered significant. Analysis was performed with IBM ${ }^{\circledR}$ SPSS Statistics V22.0.

Table 1 Patient demographics and clinical data with prehospital and emergency department parameters

\begin{tabular}{lll}
\hline Demographics and clinical data & & $n$ \\
\hline Age (years) & & \\
Men & $26[22.0-36.3]$ & 1000 \\
Women & $976(96.6 \%)$ & 1010 \\
Injury intent & $34(3.4 \%)$ & 1010 \\
Accident & & \\
Self-harm & $45(4.5 \%)$ & 1010 \\
Assault & $88(8.7 \%)$ & 1010 \\
Other & $777(76.9 \%)$ & 1010 \\
Unknown & $30(3.0 \%)$ & 1010 \\
ISS & $70(6.9 \%)$ & 1010 \\
NISS & $9[1-18]$ & 991 \\
NISS $\leq 15$ & $11[3-26]$ & 991 \\
NISS 16-24 & $4[2-9]$ & 603 \\
NISS $\geq 25$ & $18[17-22]$ & 114 \\
Prehospital SBP (mmHg) & $34[27-57]$ & 274 \\
Prehospital GCS & $130[110-144]$ & 562 \\
Prehospital RR/min & $15[15-15]$ & 660 \\
ED SBP (mmHg) & $20[18-24]$ & 521 \\
ED GCS & $135[119-150]$ & 821 \\
ED RR/min & $15[15-15]$ & 842 \\
\hline
\end{tabular}

ISS Injury Severity Score, NISS New Injury Severity Score, ED emergency department, $S B P$ systolic blood pressure, GCS Glasgow-Coma Scale, $R R$ respiratory rate

*Median [IQR]

\section{Results}

\section{Patient demographics}

This study included 1010 patients admitted with firearm injuries, $96.6 \%$ men $(n=976)$ and $3.4 \%$ women $(n=34)$ with a median age of 26.0 years [IQR 22.0-36.3] (Table 1). The median ISS was 9 [IQR 1-18] and median NISS was 11 [IQR 3-26]. The most common injury intent was assault $(76.9 \% ; n=777)$. Firearm injuries dominated in the younger population where the age group $21-30$ years $(n=442)$ was most common, followed by age group $<20$ years $(n=194)$ and 31-40 years $(n=151)$. There were fewer injuries in the population $>70$ years $(n=32)$. Nevertheless, there was an increase in all age groups over time $(P<0.001)$. The number of firearm injuries has increased over the years $(P<0.001)$ (Fig. 1). This increase was also seen for women during the study period $(P=0.001)$. The confirmed number of annual shootings on a national level in relation to the number of trauma admissions from 2017 to 2019 is displayed in Table 2 .

The majority of firearm injuries $(71.2 \%)$ occurred in the three most populated regions (Stockholm 30.4\%; Gothenburg 21.3\%; Malmo/Lund 19.5\%) in the country. A comparison of the annual distribution of firearm injuries between Sweden's three largest regions and other regions is included in Fig. 1.

\section{Clinical data}

Prehospital and emergency department (ED) vital signs are displayed in Table 1. Prehospital and ED systolic blood pressure $(\mathrm{SBP})<90 \mathrm{mmHg}$ or no palpable radial pulse was seen
Fig. 1 Annual number of firearm injuries nationwide with the distribution in the three most populated regions in relation to other regions

\section{Distribution of firearm injuries}

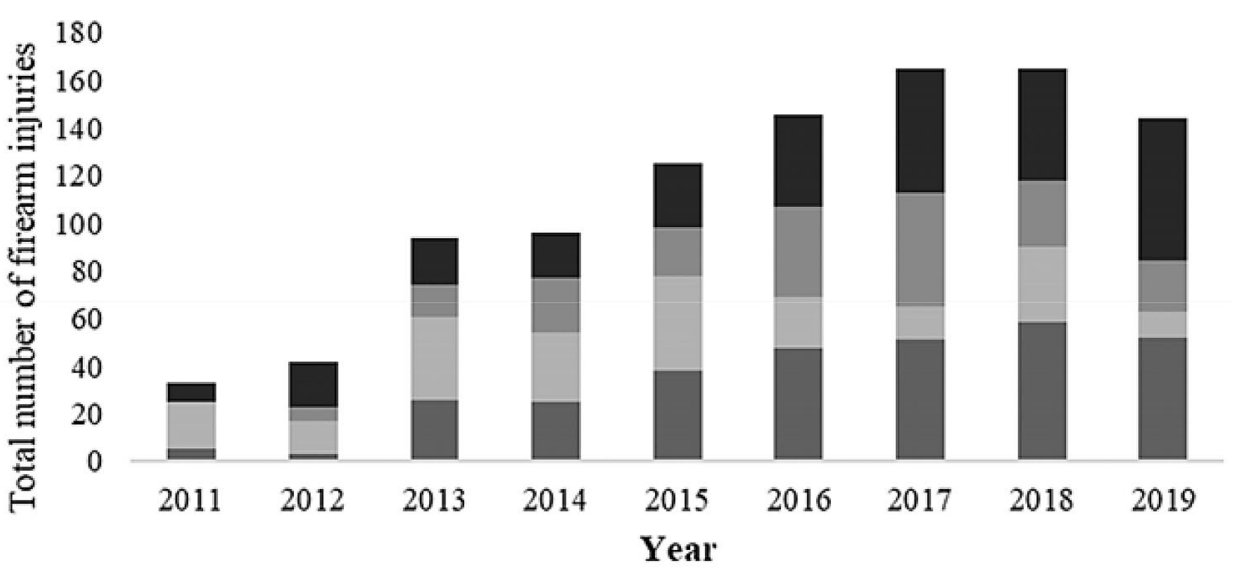

$\square$ Stockholm $\square$ Göteborg $\square$ Malmo/Lund $\quad$ Other regions 
Table 2 Confirmed illegal shootings on a national level in relation to hospital trauma admissions and mortality, including patient fatalities not reaching hospitals

\begin{tabular}{llclc}
\hline Year & $\begin{array}{l}\text { Confirmed } \\
\text { illegal shoot- } \\
\text { ings* }\end{array}$ & $\begin{array}{l}\text { Trauma } \\
\text { admis- } \\
\text { sions }\end{array}$ & $\begin{array}{l}\text { Total mortality } \\
\text { illegal shoot- } \\
\text { ings** }\end{array}$ & $\begin{array}{l}\text { In-hospital } \\
\text { mortality*** }\end{array}$ \\
\hline 2011 & NA & 33 & 17 & 3 \\
2012 & NA & 42 & 17 & 5 \\
2013 & NA & 94 & 25 & 13 \\
2014 & NA & 96 & 28 & 16 \\
2015 & NA & 125 & 33 & 20 \\
2016 & NA & 147 & 30 & 21 \\
2017 & 324 & 164 & 40 & 25 \\
2018 & 306 & 165 & 43 & 31 \\
2019 & 334 & 144 & 45 & 29 \\
\hline
\end{tabular}

$N A$ data not available

*Data from the Swedish Police Authority; registration from 2017

**Data from the Swedish National Council for Crime Prevention

***Data from the Swedish National Quality Registry for Trauma (SweTrau)

in $20.3 \%$ (142/701) and $15.3 \%$ (143/934), respectively. There were $13.0 \%$ (98/752) prehospital cardiac arrests. Prehospital and ED intubation was performed in $12.4 \%$ (92/742) and $21.6 \%$ (197/910), respectively.

The most common prehospital transportation was ground ambulance, 68.7\% (694/1010); 5.3\% $(n=54)$ arrived with helicopter, $6.8 \%(n=69)$ with private transportation, $4.3 \%$ $(n=43)$ walking, $2.5 \%(n=25)$ with police, $0.3 \%(n=3)$ with other transportations, and $12.1 \%(n=122)$ used unknown transportation.

\section{Patient injury data}

The annual distribution of injuries in each anatomical zone is presented in Table 3 . The most common anatomical injury location was lower extremity $(29.7 \%, n=585)$ followed by upper extremity $(13.8 \%, n=273)$, abdomen $(13.8 \%$, $n=272)$, chest $(12.5 \%, n=246)$, head $(11.1 \%, n=219)$, face $(5.6 \%, n=111)$, spine $(5.6 \%, n=111)$, neck $(2.9 \%, n=58)$, and unknown region $(5.0 \%, n=98)$. The head was the most severely injured body region with a median AIS of 5 [IQR $3.25-5]$. The majority of patients $(51.3 \%, n=518)$ had more than one anatomic injury location where the combination of lower extremity and abdomen dominated $(15.2 \%, n=154)$. In patients arriving in the $\mathrm{ED}$ with $\mathrm{SBP}<90 \mathrm{mmHg}$ or no palpable radial pulse $(n=143)$, anatomic injury location to the chest dominated $(69.2 \%, 99 / 143)$, followed by the lower extremity $(44.8 \%, n=64)$ and the abdomen $(42.7 \%, n=61)$.

There was a total of 175 registered vascular injuries. Most vascular injuries were located to lower extremity $(42 \%$, $n=74)$ followed by abdomen $(18 \%, n=32)$, chest $(18 \%$, $n=32)$, and upper extremity $(10 \%, n=18)$.

\section{Surgical procedures related to firearm injuries}

There were in total 1249 primary surgical procedures that were performed in 881 patients (Table 4). Wound-related surgical procedures dominated, followed by fracture surgery. There were in total 146 laparotomies and 80 thoracotomies. For patients arriving in the ED with $\mathrm{SBP}<90 \mathrm{mmHg}$ or no palpable pulse, $37.1 \%$ (53/143) underwent thoracotomy and 19.6\% $(n=28)$ laparotomy; $14.7 \%(n=21)$ experienced both laparotomy and thoracotomy. Thoracotomy was performed in 38.8\% (38/98) of patents with prehospital cardiac arrest and laparotomy in $17.3 \%(n=17)$.

\section{Patient outcome}

The median number of days on mechanical ventilation was 2 ([IQR 1-4], $n=229$ ). The median hospital length of stay was 3 days ([IQR 2-8], $n=961$ ). One hundred fifty-four patients (15.2\%) died within $24 \mathrm{~h}$ of admission of whom 90 had prehospital cardiac arrest. In patients arriving with cardiac arrest only $8.2 \%$ survived the first $24 \mathrm{~h}$. The 30 -day
Table 3 The annual distribution of injuries in anatomical zones

\begin{tabular}{lrrrrrrrrr}
\hline & Head & Face & Neck & Thorax & Abdomen & Spine & $\begin{array}{l}\text { Upper } \\
\text { extremity }\end{array}$ & $\begin{array}{l}\text { Lower } \\
\text { extremity }\end{array}$ & Unspecified \\
\hline 2011 & 5 & 3 & 3 & 9 & 13 & 7 & 8 & 17 & 4 \\
2012 & 11 & 3 & 1 & 8 & 9 & 1 & 9 & 21 & 5 \\
2013 & 25 & 11 & 1 & 15 & 21 & 9 & 23 & 60 & 12 \\
2014 & 17 & 7 & 12 & 25 & 28 & 7 & 26 & 49 & 9 \\
2015 & 32 & 17 & 7 & 31 & 38 & 14 & 41 & 67 & 10 \\
2016 & 29 & 18 & 7 & 37 & 38 & 14 & 42 & 91 & 10 \\
2017 & 41 & 17 & 13 & 43 & 53 & 21 & 41 & 96 & 13 \\
2018 & 36 & 20 & 9 & 39 & 37 & 25 & 46 & 98 & 14 \\
2019 & 23 & 15 & 5 & 39 & 35 & 13 & 37 & 86 & 21 \\
Total $(n)$ & 219 & 111 & 58 & 246 & 272 & 111 & 273 & 585 & 98 \\
\hline
\end{tabular}


Table 4 Types of surgical procedures performed due to firearm injuries

\begin{tabular}{lc}
\hline Type of surgical procedure & $\begin{array}{c}\text { Number of } \\
\text { patients }(n)\end{array}$ \\
\hline Wound suture/revision & 413 \\
Fracture surgery & 177 \\
Removal foreign body & 178 \\
Laparotomy & 146 \\
Chest tube & 118 \\
Thoracotomy & 80 \\
Open vascular & 55 \\
Fasciotomy & 45 \\
Endovascular & 15 \\
Craniotomy & 17 \\
Neck exploration & 5 \\
No surgical procedure & 129 \\
\hline
\end{tabular}

and 90-day mortality was $16.7 \%(169 / 1010)$ and $17.5 \%$ $(n=177)$, respectively. The total number of deaths was 213 (21.1\%) upon the day of data extraction and the median follow-up time was 33.3 months [IQR 10.5-60.9]. The long-term survival curve is displayed in Fig. 2.

The total firearm-related fatalities in the country from The Swedish National Council for Crime Prevention, also including patient fatalities not reaching hospitals, in relation to in-hospital mortality per year are shown in Table 2. The majority of patients were discharged from hospital directly to their homes $(60.4 \%, 610 / 1010) ; 163$ patients $(16.1 \%)$ to the morgue, and 65 patients $(6.4 \%)$ were discharged to rehabilitation.
Univariate analysis and multivariable logistic regression analyses were performed to identify risk factors associated with 24-h and 30-day mortality (Table 5). In the univariate analysis, ED SBP $<90 \mathrm{mmHg}$, NISS $\geq 25$, as well as the injuries to the head, neck, chest, abdomen, and upper extremity with AIS $\geq 3$ were associated with both 24 -h and 30-day mortality. In the multivariable analysis, there was an association between 24-h mortality and ED SBP $<90 \mathrm{mmHg}$ [OR 30.3, 95\% CI 16.1-56.9] as well as the following injuries with AIS $\geq 3$; head [OR 11.8, 95\% CI 7.5-18.5], chest [OR 2.3, 95\% CI 1.3-4.1], and upper extremity [OR 3.6, CI 1.3-10.1]. A similar injury pattern with ED SBP $<90 \mathrm{mmHg}$ [OR 37.7, 95\% CI 19.4-73.1] as well as injuries with AIS $\geq 3$ to the head [OR 12.3, 95\% CI 8.0-19.1], face [OR 5.0, 95\% CI 1.5-17.0], chest [OR 2.9, 95\% CI 1.7-5.0], and upper extremity [OR 3.3, CI 1.1-10.0] were associated with 30-day mortality.

\section{Discussion}

Violence due to firearms is a major global public health issue and frequently contributes to premature deaths with homicides being the most common cause [1-3]. This nationwide study confirms an annual increase of firearm-related injuries in Sweden that may have reached a plateau in the past 2 years. Moreover, there were approximately twice as many reported illegal shootings in the nation compared to firearm-related trauma admissions. Firearm injuries affect people of all ages, but have a disproportionate impact on young males in major cities. Furthermore, injuries to the lower extremity were most common and the dominating surgical procedures were wound-related and fracture surgery.
Fig. 2 Kaplan-Meier long-term survival curve after hospital admission from firearm injury

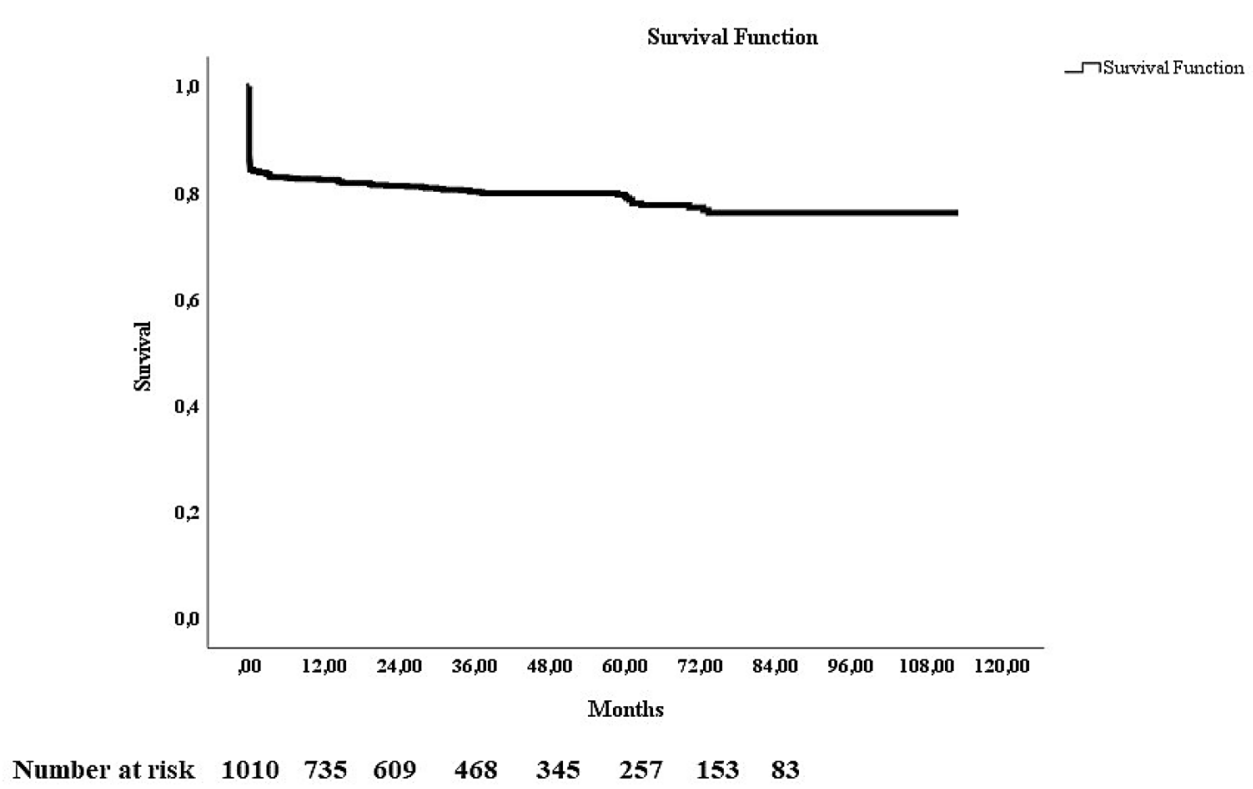


Table 5 Risk factors associated with mortality at 24-h and 30-day post-trauma admission

\begin{tabular}{|c|c|c|c|c|c|}
\hline & \multicolumn{5}{|c|}{ Odds ratio [95\% confidence interval] } \\
\hline & \multicolumn{2}{|l|}{$24 \mathrm{~h}$} & \multirow[t]{2}{*}{ 30-day } & \multicolumn{2}{|c|}{$\begin{array}{l}24 \mathrm{~h} \\
\text { Multivariable logistic regression }\end{array}$} \\
\hline & \multicolumn{2}{|c|}{ Univariate logistic regression } & & \multicolumn{2}{|c|}{ Multivariable logistic regression } \\
\hline Age & $1.01[1.00-1.02]$ & & $1.02[1.01-1.03]$ & $1.02[1.00-1.04]$ & $1.03[1.01-1.05]$ \\
\hline Female gender & $1.20[0.49-2.94]$ & & $1.28[0.55-3.00]$ & $1.16[0.48-2.80]$ & $1.01[0.42-2.44]$ \\
\hline $\mathrm{ED} \mathrm{SBP}<90 \mathrm{mmHg}$ & $28.27[15.49-51.58]$ & & $31.60[17.30-57.70]$ & $30.29[16.12-56.92]$ & 37.67 [19.42-73.09] \\
\hline \multicolumn{6}{|l|}{ NISS } \\
\hline $16-24$ & & $2.01[0.82-4.90]$ & $2.11[0.91-4.90]$ & & \\
\hline$\geq 25$ & & $21.57[12.87-36.16]$ & 23.48 [14.29-38.60] & & \\
\hline \multicolumn{6}{|c|}{ Body region with AIS $\geq 3$} \\
\hline Head & & $7.17[5.11-10.06]$ & $9.20[6.42-13.17]$ & $11.79[7.52-18.47]$ & $12.34[7.98-19.08]$ \\
\hline Face & & $0.81[0.18-3.58]$ & $3.51[1.23-10.02]$ & $2.06[0.44-9.61]$ & $5.00[1.47-16.98]$ \\
\hline Neck & & $7.71[3.34-17.79]$ & $10.10[4.16-24.47]$ & $5.17[0.60-44.19]$ & $4.83[0.51-45.64]$ \\
\hline Chest & & $4.35[3.30-5.72]$ & $4.63[3.50-6.13]$ & 2.33 [1.33-4.09] & $2.92[1.70-5.02]$ \\
\hline Abdomen & & $2.12[1.51-2.97]$ & $2.22[1.59-3.09]$ & $1.54[0.89-2.68]$ & $1.66[0.98-2.82]$ \\
\hline Spine & & $1.99[0.94-4.22]$ & $2.03[0.98-4.22]$ & $1.49[0.47-4.68]$ & $1.82[0.60-5.52]$ \\
\hline Upper extremity & & $2.38[1.26-4.51]$ & $2.10[1.11-3.98]$ & $3.61[1.28-10.16]$ & $3.34[1.11-10.00]$ \\
\hline Lower extremity & & $0.58[0.40-0.86]$ & $0.57[0.39-0.82]$ & 0.53 [0.29-0.99] & $0.52[0.28-0.95]$ \\
\hline
\end{tabular}

Firearm-related fatalities have overall increased annually in the nation. One in six patients succumbed from their injuries within 30 days with most deaths occurring within $24 \mathrm{~h}$ of admission to hospital.

Recent studies suggest that firearm injuries have an upward trend in high-income countries, resulting in increased hospitalization $[12,13]$. Avraham et al. showed an increase in firearm-related injuries treated in the US which are primarily instigated by injuries to young adults causing significant overall mortality of $7.8 \%$ [14]. Our study was no exception and showed an annual rise in the total number of GSW. In general, with some annual variations, there was an increase in firearm injuries both in populated and less populated regions. It has been suggested that men are more likely to be hospitalized for GSW but less likely to die [15]. Despite a few cases of women being reported, we noted an annual increase of firearm-related injuries in women that needs further analysis. We could not find any associations between gender and outcome which might be explained by the low number of women reported in this registry. Previous studies have shown a higher rate of assault by intimate partners, increased incidence of pre-existing mental illness, more frequent injury to the extremities, and a shorter ICU stay in women [15, 16]. Moreover, it has been suggested that firearm injuries due to gun violence are overrepresented in some socioeconomic and demographic subgroups which were not possible to investigate in-depth in this study [17].

There were about $20 \%$ of patients with prehospital hemodynamic instability. These patients had injuries mainly located to the chest, lower extremity, and abdomen. The majority underwent emergent laparotomy or thoracotomy. Hemodynamic instability was not surprisingly associated with mortality. This is in line with a previous study from the National Trauma Data Bank (NTDB), showing that every SBP drop of $10 \mathrm{mmHg}$ increased mortality with $4.8 \%$ in patients with SBP of $110 \mathrm{mmHg}$ and lower [18]. In a previous Swedish study, Ghorbani et al. showed that hemorrhage was the cause of deaths in $70 \%$ of all penetrating trauma [19]. This suggest that death due to hemorrhage still remains the most common preventable cause of death after firearm injuries, and early recognition of shock is essential [20, 21]. Furthermore, additional analysis of firearm-related trauma deaths may identify preventable measures and areas of improvement in clinical management [20].

This study found the extremities to be the dominating anatomic region for firearm injuries. This is supported by other studies, showing that the extremities are the most commonly injured anatomic regions in non-fatal GSW [22]. More than $40 \%$ of vascular injuries were located to the lower extremities. Compressible bleeding and the more frequent use of tourniquets may explain hemodynamic stability in this patient group. In a study by Berg et al., gunshot-related fractures occurred in one-fifth of patients which increased the risk of vascular and nerve injury [22]. The majority of injuries in this study were located to more than one body region where the lower extremity combined with the abdomen was most common. In patients with hemodynamic instability and GSWs to the lower quadrants of the abdomen and groins, there may be a need for exploratory laparotomy to achieve rapid proximal vascular control and haemostasis. There was 
no anatomic body region that increased in numbers over time. The most severely injured body region was the head which was associated with 24-h and 30-day mortality.

A retrospective registry review of patients treated for GSW at an urban major trauma center in the US showed that $75 \%$ of patients admitted to hospital needed at least one surgical procedure during hospitalization [23]. Moreover, it has been suggested that systolic hypotension, hypothermia, and tachycardia are associated with an increased likelihood of surgical intervention [24]. In our population, $87 \%$ of patients admitted to hospital underwent one or more surgical procedure. The most common procedure was wound -related surgery $(30.0 \%)$, followed by removal of foreign body $(12.9 \%)$ and fracture surgery $(12.8 \%)$. The number of performed laparotomies and thoracotomies nationwide are lower compared to a previous study from an urban university trauma centre which potentially could be explained by different experiences and management protocols [8].

American College of Surgeons (ACS) National Trauma Data Bank reported a 30-day mortality rate of $15.3 \%$ after firearm injuries [25]. The outcome is similar in this study with a 24 -h mortality of $15.2 \%$, and 30 - and 90-day mortality of 16.7 and $17.5 \%$, respectively. This supports the notion that firearm-related mortality occurs most frequently within $24 \mathrm{~h}$. High NISS and hemodynamic instability are important mortality predictors, and head injury is especially lethal and confirmed by other studies [8, 26, 27].

There are limitations inherent to retrospective national registry studies including limited variables and missing data for specific variables. However, population-based data reflects real-life experience and the results may be applicable in a wider perspective. The SweTrau inclusion criteria may underestimate the number of firearm injuries, but these criteria are according to the established templates for uniform reporting of data following major trauma [28]. Additionally, patients that were already dead at the scene due to gun violence were not included in the study. Hence, potential differences in this patient group were not possible to investigate or analyze due lack of specific data.

The Swedish trauma registry was founded and implemented less than a decade ago. There may be a risk of missing patients due to lack of registration. The registry data were scrutinized for the three largest trauma centers in the country and potentially missed registered patients with firearm-related injuries were added. Furthermore, patients that had been registered twice due to transportation to a trauma centre were excluded. To adjust for variation in data quality and completeness, standardized data techniques were used, and missing values imputed by combining numeric and ordinal values. Nevertheless, some of the data analyzed were based on coding and might be subject to variations in practice. Registry data were combined with open access data from other authorities. The use of different data sources in parallel can provide a more complete understanding of the firearm injury epidemiology.

In conclusion, this study explored nationwide epidemiology of firearm injuries and assessed anatomical distribution of injuries, operative procedures, and outcomes. An overall increase of firearm injuries has occurred over the years, but may have plateaued in recent years. Firearm injuries remain an important public health problem and continue to cause significant morbidity and mortality. The lower extremity was the most common injury location but injuries to the head most lethal. The majority of injuries occurred in populated regions, but an increase was also seen in less urban areas which emphasize the importance of robust trauma systems with an appropriate field triage to transport patients to the nearest possible appropriate hospital. Given the economic and social impact of firearm injuries, as well as implementation of policy and public health efforts to reduce gun violence, additional population-based research is imperative.

Acknowledgements This study was made possible with support from the Swedish Carnegie Foundation and the Swedish National Quality Registry for Trauma (SweTrau). Maria Ioanna Kotopouli, Division of Biostatistics, Institute of Environmental Medicine, Karolinska Institute, Solna, Sweden, for statistical support.

Author contribution $\mathrm{KN}$ : responsible for data collection and analyzation, and interpretation of the results, and wrote the initial draft of the manuscript, and provided important revisions and edits. ECC and PD: provided and helped collect additional data, made important revisions and edits, and approved the final version of the manuscript. CMW: conceived and designed the study, obtained IRB approval, acquired and helped analyze the data, helped interpret the results, made critical revisions, and had final approval of the version to be published.

Funding Open access funding provided by Karolinska Institute. This study was funded by the Swedish Carnegie Fund.

\section{Declarations}

Conflict of interest The authors declare no conflicts of interest.

Ethical approval The study was approved by ethics committee and has been performed in accordance with the ethical standards laid down in the 1964 Declaration of Helsinki and its later amendments.

Open Access This article is licensed under a Creative Commons Attribution 4.0 International License, which permits use, sharing, adaptation, distribution and reproduction in any medium or format, as long as you give appropriate credit to the original author(s) and the source, provide a link to the Creative Commons licence, and indicate if changes were made. The images or other third party material in this article are included in the article's Creative Commons licence, unless indicated otherwise in a credit line to the material. If material is not included in the article's Creative Commons licence and your intended use is not permitted by statutory regulation or exceeds the permitted use, you will need to obtain permission directly from the copyright holder. To view a copy of this licence, visit http://creativecommons.org/licenses/by/4.0/. 


\section{References}

1. Taichman DB, Bauchner H, Drazen JM, Laine C, Peiperl L. Firearm-related injury and death-a U.S. health care crisis in need of health care professionals. JAMA. 2017;318(19):1875.

2. The Global Burden of Disease 2016 Injury Collaborators. Global mortality from firearms, 1990-2016. JAMA. 2018;320(8):792-814.

3. Winfield RD, Crandall M, Williams BH, Sakran JV, Shorr K, Zakrison TL. Firearm violence in the USA: a frank discussion on an American public health crisis-the Kansas City Firearm violence symposium. Trauma Surg Acute Care Open. 2019;4(1): e000359.

4. Perkins ZB, De'Ath HD, Aylwin C, Brohi K, Walsh M, Tai NR. Epidemiology and outcome of vascular trauma at a British major trauma centre. Eur J Vasc Endovasc Surg. 2012;44(2):203-9.

5. Inkinen JKK, Gunn J, Kuttila K. Penetrating trauma; experience from Southwest Finland between 1997 and 2011, a retrospective descriptive study. Eur J Trauma Emerg Surg. 2015;41(4):429-33.

6. Dobaria V, Aguayo E, Sanaiha Y, Tran Z, Hadaya J, Sareh S, Cho NY, Benharash P. National trends and cost burden of surgically treated gunshot wounds in the US. J Am Coll Surg. 2020;231(4):448-59.

7. Hink ABBS, Levy M, Kuhls DA, Allee L, Burke PA, Sakran JV, Bulger EM, Stewart RM. Firearm injury research and epidemiology: a review of the data, their limitations, and how trauma centers can improve firearm injury research. J Trauma Acute Care Surg. 2019;87(3):678-89.

8. Bäckman PB, Riddez L, Adamsson L, Wahlgren CM. Epidemiology of firearm injuries in a Scandinavian trauma center. Eur J Trauma Emerg Surg. 2020;46(3):641-7.

9. Swetrau (2019) Årsrapport SweTrau 2019 [internet]. Annual report. Stockholm: Svenska Traumaregister. http://rcsyd.se/swetr au/wp-content/uploads/sites/10/2020/09/A\%CC\%8ArsrapportSweTrau-2019.pdf. Accessed 2020.

10. Gennarelli TA, Wodzin E. AIS 2005: a contemporary injury scale. Injury. 2006;37(12):1083-91.

11. Champion HRSW, Copes WS, Gann DS, Gennarelli TA, Flanagan ME. A revision of the Trauma Score. J Trauma. 1989;29(5):623-9.

12. Christensen MCNT, Ridley S, Lecky FE, Morris S. Outcomes and costs of penetrating trauma injury in England and Wales. Inj Int J Care Inj. 2008;39(9):1013-25.

13. Cook AOT, Hosmer D, Glance L, Rogers F, Gross B, GarciaFilion P, Malhotra A. Gunshot wounds resulting in hospitalization in the United States: 2004-2013. Injury. 2017;48(3):621-7.

14. Avraham JB, Frangos SG, DiMaggio CJ. The epidemiology of firearm injuries managed in US emergency departments. Inj Epidemiol. 2018;5(1):38.

15. Nagengast AB, Benns MW, Bozeman MC, Nash NA, Smith JW, Harbrecht BG, Franklin GA, Miller KR. Firearm injuries in women at an urban trauma center. J Am Coll Surg. 2017;225(4):178.
16. Resnick S, Smith RN, Beard JH, Holena D, Reilly PM, Schwab $\mathrm{CW}$, Seamon MJ. Firearm deaths in America: can we learn from 462,000 lives lost? Ann Surg. 2017;266(3):432-40.

17. Zebib L, Stoler J, Zakrison TL. Geo-demographics of gunshot wound injuries in Miami-Dade county, 2002-2012. BMC Public Health. 2017;17:174.

18. Brown JB, Gestring ML, Forsythe RM, Stassen NA, Billiar TR, Peitzman AB, Sperry JL. Systolic blood pressure criteria in the National Trauma Triage Protocol for geriatric trauma: 110 is the new 90. J Trauma Acute Care Surg. 2015;78(2):352-9.

19. Ghorbani P, Falkén M, Riddez L, Sundelöf M, Oldner A, Strömmer L. Clinical review is essential to evaluate 30-day mortality after trauma. Scand J Trauma Resusc Emerg Med. 2014;22(1):18.

20. Ghorbani P, Strömmer L. Analysis of preventable deaths and errors in trauma care in a Scandinavian trauma level-I centre. Acta Anaesthesiol Scand. 2018;00:1-8.

21. Deane M, Galvagno SM Jr, Moran B, Stein DM, Scalea TM, O'Connor JV. Shock, not blood pressure or shock index, determines the need for thoracic damage control following penetrating trauma. Shock. 2020;54(1):4-8.

22. Berg RJ, Okoye O, Inaba K, Konstantinidis A, Branco B, Meisel E, Barmparas G, Demetriades D. Extremity firearm trauma: the impact of injury pattern on clinical outcomes. Am Surg. 2012;78(12):1383-7.

23. Livingston DH, Lavery RF, Lopreiato MC, Lavery DF, Passannante MR. Unrelenting violence: an analysis of 6,322 gunshot wound patients at a level I trauma center. J Trauma Acute Care Surg. 2014;76(1):2-9.

24. Azad AD, Kong VY, Clarke DL, Laing GL, Bruce JL, Chao TE. Use of vital signs in predicting surgical intervention in a South African population: a cross-sectional study. Int J Surg. 2020;79:300-4.

25. National Trauma Data Bank (2016) National Trauma Data Bank, Annual Report 2016. Chicago: American College of surgeons. https://www.facs.org/ /media/files/qualityprograms/trauma/ntdb/ ntdbannualreport2016.ashx. Accessed 2016

26. Aarabi B, Tofighi B, Kufera JA, Hadley J, Ahn ES, Cooper C, Malik JM, Naff NJ, Chang L, Radley M, Kheder A, Uscinski RH. Predictors of outcome in civilian gunshot wounds to the head. J Neurosurg. 2014;120(5):1138-46.

27. Skarupa DJ, Khan M, Hsu A, Madbak FG, Ebler DJ, Yorkgitis B, Rahmathulla G, Alcindor D, Joseph B. Trends in civilian penetrating brain injury: a review of 26,871 patients. Am J Surg. 2019;218(2):255-60.

28. Ringdal KG, Coats TJ, Lefering R, Di Bartolomeo S, Steen PA, Røise O, Handolin L, Lossius HM, Utstein TCD Expert Panel. The Utstein template for uniform reporting of data following major trauma: a joint revision by SCANTEM, TARN, DGU-TR and RITG. Scand J Trauma Resusc Emerg Med. 2008;16:7. 


\section{Authors and Affiliations}

\section{Karolina Nyberger $^{1,2} \cdot$ Eva-Corina Caragounis $^{3} \cdot$ Pauline Djerf $^{4} \cdot$ Carl-Magnus Wahlgren $^{1,2}$ (i)}

Karolina Nyberger

karolina.nyberger@gmail.com

Eva-Corina Caragounis

eva-corina.caragounis@gu.se

Pauline Djerf

paulinedjerf@yahoo.se

1 Department of Molecular Medicine and Surgery, Karolinska Institute, Solna, Sweden
2 Department of Vascular Surgery, Karolinska University Hospital, SE-171 76 Stockholm, Sweden

3 Department of Surgery, Institute of Clinical Sciences, Sahlgrenska University Hospital, Sahlgrenska Academy, University of Gothenburg, Gothenburg, Sweden

4 Department of Surgery, Lund University, Skåne University Hospital, Lund, Sweden 